\title{
EPNOE 2013 conference
}

\author{
Patrick Navard
}

Received: 25 March 2013/Accepted: 27 March 2013/Published online: 13 April 2013

(C) Springer Science+Business Media Dordrecht 2013

EPNOE 2013: the 3rd EPNOE International Polysaccharide Conference on "Polysaccharides and polysaccharide-derived products. From basic science to applications" will be held in Nice (France) on 21-24 October 2013. EPNOE 2013 is co-organised by EPNOE (European Polysaccharide Network of Excellence) and the Cellulose and Renewable Materials Division of the American Chemical Society (ACS), these two societies joining their efforts in promoting basic and applied sciences of polysaccharides by organising common events.

EPNOE and ACS are expecting EPNOE 2013 conference to be a forum bringing together academic, industrial, and government scientists and students dealing with polysaccharides and polysaccharidederived products. Many disciplines including biologists, chemists, physicists, food specialists, technologists, and environmentalists will meet and gain knowledge about the interdisciplinary world of polysaccharide science.

Fifteen topics, a round-table discussion on education, an evening session for the general public, a special session entitled "Polysaccharide-based bio-economy: visions of CEOs and major stakehoders" and a preconference course on bioplastics are planned. In

P. Navard $(\square)$

Mines ParisTech, Centre de Mise en Forme des Matériaux (CEMEF), CNRS UMR 7635, CS 10207, 1 Rue Claude Daunesse, 06904 Sophia Antipolis Cedex, France e-mail: patrick.navard@mines-paristech.fr

URL: www.epnoe.eu addition to oral and poster presentations, four plenary lecturers and more than 30 keynote and invited lecturers from all over the world will deliver talks. Thomas Heinze (university of Jena, Germany) and Hans-Peter Fink (Fraunhofer Society, Gölm, Germany), both EPNOE scientists and recent recipients of the ACS Anselme Payen award, will be our Special Guests.

We hope to see you in Nice, a city ideally located between the high mountains of Alps and sea, with a very comfortable climate in October. The conference will take place in the newly restored Acropolis Congress Hall of Nice, situated in the heart of the old city, a few hundred meters from the Mediterranean Sea.

All information is available at http://epnoe2013. sciencesconf.org.

EPNOE (www.epnoe.eu) is an active network dealing with all aspects of polysaccharide science and technology. It is composed of 16 European research or academic institutions and many companies. Its main role is to install efficient tools for favoring postgraduate mobility between institutions, research projects and academia-industry knowledge transfer. One of the latest activities is the "Dormant Ideas" initiative. EPNOE members have gathered in the "Dormant Ideas Box" hundreds of ideas they have not been able to develop for many reasons (lack of time, out of main strategy, unable to see an application...) in order to create new values out of them. 